\title{
EFEITOS DE REGULADORES DE CRESCIMENTO NA FRUTIFICAÇÃO DO TOMATEIRO CULTIVAR «MIGUEL PEREIRA»**
}

\author{
Paulo R. C. Castro ** \\ Eurípedes Malavolta ***
}

RESUMO

Estudaram-se em condições de campo (Piracicaba, SP), os efeitos da aplicação de reguladores de crescimentos no peso, número e peso médio dos frutos de tomateiro cultivar "Miguel Pereira". Quando as plantas apresentavam quatro folhas definitivas efetuou-se a pulverização com cloreto de (2-cloroetil) trimetilamônio $2.000 \mathrm{ppm}$, ácido succínico $-2,2$ - dimetillidrazida 3.000 ppm, ácido giberélico $200 \mathrm{ppm}$ e ácido (2-cloroetil) fosfônico $200 \mathrm{ppm}$. Verificout-se que o CCC, CEPA, GA e SADH, não afetaram o peso total dos frutos de tomateiro. Os reguladores de crescimento não promoveram variação no número de frutos produzidos. Observou-se que tratamcitos com CCC e CEPA não afetaram o peso médio do fruto; sendo que aplicação de S.ADH e GA reduziu o peso médio do fruto.

\section{INTRODUÇÃO}

O conhecimento dos efeitos de reguladores de crescimento em tomateiro reveste-se de interesse, por tratar-se de uma cultura em que se utiliza de avançadas técnicas de cultivo em nossas condições. Os reguladores de crescimento têm sido utilizados para induzir o florescimento, aumentar a dimensão e a fixação dos frutos e provocar o amadurecimento.

\footnotetext{
* Trabalho subvencionado pelo Conselho Nacional de I)esenvolvimento Científico e Tecnológico (C.NPq); parte da Tese apresentada pelo primeiro autor para obtenção do título de Doutor pela U.S.P.; Entregue para pułlicação em 17/08/76.

** Departamento de Botânica. E.S.A. "Luiz de Queiroz" -- U.S.P.

* Departamento de Química e CENA. E.S.A. "Luiz de Queirez" - U.S.P. OBs.: Considerar aspas duplas referentes às cultivares como sendo arpus simples.
} 
Diversos retardadores de crescimento vegetal, como o cloreto de (2-cloroetil) trimetilamônio (CCC), quando aplicados às raízes de plantas de tomateiro alteraram o crescimento e promoveram florescimento precoce. O ácido succínico -2,2- dimetilhidrazida (SADH) induziu aumento de produção e uniformidade na maturação. Aplicação de auxina, ácido 4-clorofenoxiacético, em tomateiros cultivados em casa de vegetação, aumentou a fixação dos frutos. A utilização do ácido (2-cloroetiil) fosfônico (CEPA) acelerou a iniciação da maturação em frutos de tomateiro (WEAVER, 1972).

CASTRO \& CHURATA-MASCA (1973 b) verificaram que a aplicação de CCC na concentração de 4.000 ppm, em irrigação, promoveu aumento no número de frutos por planta de tomateiro. Observaram que o peso total de frutos por planta também foi significativamente afetado, promovendo as maiores médias de produtividade as concentrações de $4.000 \mathrm{ppm}$ em irrigação e $2.000 \mathrm{ppm}$ sob a forma de pulverização. $O$ peso médio dos frutos não foi afetado pelos tratamentos. CHURATA-MASCA \& CASTRO (1975) notaram que CCC aplicado em tomateiros, aos 40 e 55 dias após a semeadura, nas dosagens de 0,5 ou 1,0 l/ha, promoveu aumentos relativos na produção comercial de tomates destinados à indústria. As médias de produção em $t / h a$, entretanto, não chegaram a diferir significativamente. READ \& FIELDHOUSE (1970) observaram aumento na produção de tomateiros com a pulverização de SADH e de CCC. Os tratamentos mais eficientes foram obticlos com SADH $2.500 \mathrm{ppm}$, aplicado em tomateiros com a primeira folha verdadeira, com a quarta folha verdadeira, ou em ambos estágios de crescimento. Conseguiram concentração no período de colheita e precocidade, com aplicação posterior de SADH 5.000 ppm, para o desbaste floral, após terem obtido a fixação da quantidade desejada de frutos. O último tratamento tem implicações desejáveis para a colheita mecanizada, desde que virtualmente elimina os frutos verdes indesejáveis e torna lento o crescimento vegetativo, promovendo uma colheita mais concentrada devidon a maturação mais rápida dos frutos. Os aumentos em produção foram atribuídos a uma cornbinação de efeitos, incluindo resistência ao əfeito estressor da água $e$ calor, mais flores por cacho (cacho de cimeira) e mais frutos por planta.

MIRANDA NETO \& CHAVES (1969) verificaram aumento na precocidade de produção em tomateiros tratados com ácido giberélico 100 ppm e com ácido giberélico $50 \mathrm{ppm}+50 \mathrm{ppm}$ de ácido para clorofenoxiacético; sendo que não foram observadas diferenças na produção total de frutos. Notaram ocorrência variável de frutos partenocárpicos; sendo que o peso médio dos frutos também apresentou variações diversas com a aplicação dos reguladores de crescimento. Observaram ainda uma tendência de diminuição no peso médio em conseqüência de aumento no número de frutos. CASTRO et alii (1972a) verificaram partenocarpia em frutos de tomateiro tratados com ácido 2-hidroximetil 4-clorofenoxiacético. Os tratamentos com 150, 200 e 300 ppm diminuiram a pro- 
dução total de frutos, reduzindo também o peso médio dos frutos. Observaram a ocorrência de lóculos verdes em parte dos frutos de pequenas dimensões, deformados e partenocárpicos, encontrados em relativamente baixa freqüência no tratamento com auxina a 300 ppm, especialmente nas últimas colheitas. CASTRO \& CHURATA-MASCA (1973 a) observaram que o ácido 2-hidroximetil 4-clorofenoxiacético, aplicado na concentração de $300 \mathrm{ppm}$, promoveu aumento no peso médio dos frutos, em cerca de 5 a 10 gramas por fruto, até a quarta colheita, com relação ao controle. Verificaram uma alteração na curva de distribuição do número de frutos colhidos, quando relacionaram tratamentos com 150 e 300 ppm da auxina, e o controle. GUSTAFSON (1960) estudando comparativamente a ação do ácido indolacético (IAA), ácido 2, 3, 6-triclorobenzóico e o ácido giberélico, observou que somente 0,5 a $1 \%$ de ácido giberélico induziram a formação de frutos partenocárpicos. Quando os botões florais e as flores dos três primeiros cachos eram pulverizados com giberelina 35 e 70 ppm, o número de frutos era aumentado, mas seu peso total era reduzido. Quando somente o primeiro cacho era pulverizado, o número de frutos produzidos e o peso total por cacho eram aumentados, porém esta resposta não ocorreu nos cachos seguintes.

GRAY (1957) observou um eficiente efeito de giberelinas estimulando o crescimento do tomateiro, quando aplicadas no transplante. O florescimento não foi atrasado pela aplicação do produto. Considerou que a pulverização com giberelina $50 \mathrm{ppm}$ pode aumentar a produção em 40 por cento; sendo que as plantas tratadas com giberelinas apresentaram maior número de frutos verdes por ocasião da colheita, em relação ao controle. SIMÃO et alii (1958) observaram redução no número total de frutos do tomateiro com aplicação de giberelina. SAWHNEY \& GREYSON (1971) verificaram, em condições de campo e de casa de vegetação, que o ácido giberélico promove aumento no tamanho dos frutos de tomateiro. Observaram aproximadamente $50 \%$ de aumento no peso médio e no diâmetro dos frutos tratados com o regulador de crescimento. RASPEVIN (1963) aplicou giberelinas $100 \mathrm{ppm}$ em tomateiros, 20 dias após a emergência, utilizando $5 \mathrm{ml}$ por planta. Observou $400 \%$ de precocidade e aumento no peso total dos frutos da ordem de $40 \%$. Verificou também melhoria na qualidade. Pulverização durante o florescimento aumentou o número de frutos, mas reduziu o peso médio dos mesmos. Tratamento com giberelinas em plantas que receberam insuficiente nutrição, causou deformação nos frutos produzidos. NEGRUCKIJ (1960) observou que aplicação de ácido giberélico 0,02\% promoveu aumento na produção e no crescimento de tomateiros, causou porém severas deformações nos frutos, principalmente nas colheitas finais. Baixas concentrações de ácido giberélico não afetaram a forma dos frutos, mas proporcionaram um pequeno aumento no crescimento.

AWAD et alii (1975) verificaram que a imersão de frutos do tomateiro em soluções de CEPA, nas dosagens de 1.000 e 2.000 ppm, mostrou 
uma aceleração na maturação; sendo que a imersão em soluções de giberelina, nas concentrações de 50 e $100 \mathrm{ppm}$, resultou em um atraso irregular na maturação. BABBITT et alii (1973) verificaram que substâncias reguladoras de crescimento afetam apenas moderadamente a ascensão do climatérico, mas influem de forma marcante no intervalo de tempo para atingir o pico do climatérico. Algumas mudanças como amaciamento, formação da cor e atividades enzimáticas da celulase e poligalacturonase, foram aceleradas por CEPA e por $\mathrm{SADH}$; sendo atrasadas por ácido giberélico e IAA. O ácido giberélico impede a atividade da poligalacturonase. Depois de 14 dias, a atividade da poligalacturonase no controle mostrou-se 25 vezes superior a dos frutos tratados com ácido giberélico. A atividade da celulase em frutos tratados com ácido giberélico aumenta uniformemente durante esse período. A perda em firmeza nos frutos tratados, sugere que o amaciamento é iniciado pela ação de enzimas celulolíticas e então as enzimas pectinolíticas são envolvidas nas alterações subseqüentes em textura. SIMS (1969) efetuou a aplicação de CEPA em tomateiros, quando 50 por cento dos frutos estavam vermelhos. Verificou na colheita, 15 dias depois, que não ocorreram diferenças significativas entre os tratamentos, no que se refere à produção, pH ou porcentagem de sólidos solúveis. Observou que aumentos na dosagem de CEPA promovem maior precocidade na maturação dos frutos. IWAHORI et alii (1969) observaram que CEPA na concentração de $1.000 \mathrm{ppm}$ promove precocidade na colheita sem alterar a produção total de frutos do tomateiro. Verificaram que CEPA 250 ppm aumentou a colheita e acelerou a maturação dos frutos. Consideraram que o tratamento com CEPA promove uma tendência de diminuição no tamanho dos frutos, sem diferir significativamente do controle. $O$ regulador de crescimento mostrou não afetar a qualidade dos frutos, no que se refere ao $\mathrm{pH}$, acidez e sólidos solúveis totais. CASTRO et alii (1972 b) observaram que aplicação do CEPA acelerou significativamente a maturação nos frutos de tomateiro. Verificaram incremento no peso e no número total de frutos por planta, obtidos nas primeiras colheitas, sendo isso compensado por diminuições significativas em colheitas posteriores. Não notaram porém, diferenças significativas no peso e número de frutos por planta, considerando a totalidade das colheitas, entre o controle e as plantas tratadas com 1.000, 2.000 e 4.000 ppm de CEPA.

O presente trabalho teve como finalidade estudar os efeitos de reguladores de crescimento no peso, número e peso médio dos frutos do tomateiro.

\section{MATERIAIS E MÉTODOS}

O experimento foi conduzido nas instalações do Departamento de Agricultura e Horticultura da Escola Superior de Agricultura "Luiz de Queiroz", em Piracicaba, Estado de São Paulo. A semeadura foi efetuada 
em 17 de fevereiro de 1974, sendo utilizados recipientes de polietileno de tamanho $11 \times 6 \mathrm{~cm}$, para a produção das mudas de tomateiro cultivar "Miguel Pereira". Procedeu-se desta forma, a fim de garantir o número desejado de plantas por parcela experimental.

O transplante foi realizado em $01 / 03 / 74$. O solo caracterizou-se como uma Terra Roxa Estruturada da série Luiz de Queiroz. Sua análise apresentou 1,6\% de carbono orgânico; pH 6,2; H, Ca + Mg e K (catiônios trocáveis) nos teores de, respectivamente, 6,6, 9,2 e 0,73 e.mg/100 g; finalmente 9,9 e.mg/100 $\mathrm{g}$ em soma de bases.

As adubações de plantio foram de 8 gramas de sulfato de amônio $(20 \%$ de $\mathrm{N}), 7$ gramas de superfosfato simples $\left(20 \%\right.$ de $\left.\mathrm{P}_{2} \mathrm{O}_{\tilde{5}}\right)$ e 5 gramas de cloreto de potássio $\left(60 \%\right.$ de $\left.\mathrm{K}_{2} \mathrm{O}\right)$ por planta. Os adubos foram misturados com o solo antes do transplante das mudas. Posteriormente, aos 20 dias do transplante, o solo foi adubado em cobertura com 8 gramas de sulfato de amônio e 5 gramas de cloreto de potássio por planta. Aos 40 e 60 dias aplicou-se mais 10 gramas de sulfato de amônio em cobertura. O estaqueamento, amarrio, irrigação e outros tratos culturais foram realizados conforme CÁSSERES (1971).

Neste experimento utilizou-se o cloreto de (2-cloroetil) trimetilamônio (CCC), o ácido succínico -2,2-dimetilhidrazida (SADH), o ácido giberélico (GA) e o ácido (2-cloroetil) fosfônico (CEPA).

O delineamento experimental foi em blocos ao acaso, (GOMES, 1963) tendo-se utilizado 6 blocos. A parcela experimental constou de 2 fileiras com 4 plantas cada uma, totalizando 8 plantas. Procedeu-se a comparação de médias pelo teste de Tukey, calculando-se a diferença mínima significativa (D.M.S.) ao nível de $5 \%$ de probabilidade.

A aplicação dos reguladores de crescimento foi efetuada em 27/03/74, por pulverização; sendo que nesta ocasião as plântulas apresentavam 4 folhas definitivas. Além do tratamento controle aplicou-se CCC na concentração de 2.000 ppm, SADH 3.000 ppm, GA 200 ppm e CEPA 200 ppm.

Os frutos produzidos foram coletados em 4 épocas: 28/05/74, 12/06/74, 27/06/74 e 08/07/74. Após cada colheita determinou-se o peso, o número e o peso médio dos frutos. O peso dos frutos foi determinado com precisão de 0,1 grama em uma balança Mettler P1200N. Realizou-se a análise do peso total e do número total de frutos colhidos por parcela constituída de 8 plantas; sendo que o peso médio dos frutos. por planta, foi também submetido à análise estatística. 


\section{RESULTADOS}

Tabela 1 - Efeito da aplicação de reguladores de crescimento no peso total em gramas, de frutos colhidos por parcela constituída de 8 plantas de tomateiro.

\begin{tabular}{lllllrrr}
\hline Tratamento & \multicolumn{9}{c}{ Repetições } & & \multirow{2}{*}{ Média } \\
\hline Controle & 7794,50 & 7806,70 & 4899,80 & 6222,30 & 4099,00 & 7636,70 & 6409,8333 \\
CCC & 8103,60 & 9409,20 & 6480,70 & 7363,80 & 7254,90 & 10402,10 & 8169,0499 \\
SADH & 5611,20 & 7336,10 & 3507,80 & 6339,40 & 3153,40 & 4557,00 & 5084,1499 \\
GA & 4946,80 & 7692,60 & 5605,60 & 7230,20 & 2821,80 & 7890,40 & 6031,2333 \\
CEPA & 5279,50 & 5449,50 & 6049,80 & 5222,00 & 5995,00 & 8216,10 & 6035,3166 \\
\hline
\end{tabular}

O teste $\mathrm{F}$ para tratamentos apresentou valor de 5,7864, significativo ao nível de $1 \%$ de probabilidade. Isto revela a presença de diferenças entre os tratamentos. A diferença mínima significativa pelo teste de Tukey, ao nível de 5\% de probabilidade, foi da ordem de 1988,5913. Verificando-se as diferenças entre as médias, observamos que as plantas tratadas com CCC apresentaram peso total em gramas, de frutos colhidos por parcela constituída de 8 plantas de tomateiro, superior aos demais tratamentos. Plantas pulverizadas com CCC mostraram maior peso total de frutos, em relação aos tomateiros tratados com SADH, GA e CEPA. Não se observou diferença significativa entre as plantas tratadas com CCC e o controle. O coeficiente de variação foi de $18,14 \%$.

Tabela 2 - Efeito da aplicação de reguladores de crescimento no número de frutcs, transformado em $\sqrt{\mathrm{x}}$, colhidos por parcela constituída de 8 plantas de tomateiro.

\begin{tabular}{|c|c|c|c|c|c|c|c|}
\hline \multirow{2}{*}{$\begin{array}{l}\text { Tratamento } \\
\text { Controle }\end{array}$} & \multirow[b]{2}{*}{7,810} & \multicolumn{3}{|c|}{ Repetições } & \multirow[b]{2}{*}{5.291} & \multirow[b]{2}{*}{7,874} & \multirow{2}{*}{$\begin{array}{r}\text { Média } \\
7,0326\end{array}$} \\
\hline & & 7,615 & 6,324 & 7,280 & & & \\
\hline CCC & 8,062 & 8,831 & 7,416 & 7,681 & 7,745 & 9,165 & 8,1504 \\
\hline SADH & 7,483 & 8,660 & 6,164 & 7,348 & 5,830 & 6,403 & 6,9817 \\
\hline GA & 7,549 & 9,000 & 7,615 & 8,774 & 5,567 & 9,110 & 7,9364 \\
\hline CEPA & 6,480 & 6,708 & 6,557 & 6,557 & 6,708 & 8,544 & 6,9260 \\
\hline
\end{tabular}

O teste $\mathrm{F}$ para tratamentos mostrou valor da ordem de 3,9522 significativo ao nível de $5 \%$ de probabilidade. A diferença mínima significativa pelo teste de Tukey, ao nível de 5\% de probabilidade, foi 
de 1,2521. Observando-se as diferenças entre as médias, notamos que não é possível verificar distinções entre as mesmas através do teste de comparação de médias utilizado. Consideramos, portanto, que a aplicação de reguladores de crescimento não afetou o número total de frutos produzidos no tomateiro. O coeficiente de variação foi da ordem de $9,79 \%$.

Tabela 3 - Efeito da aplicação de reguladlores de crescimento no peso médio em gramas, do fruto do tomateiro.

\begin{tabular}{lrrrrrrr}
\hline Tratamento & \multicolumn{9}{c}{ Repetições } & & Média \\
\hline \hline Controle & 127,80 & 134,60 & 122,50 & 117,40 & 146,40 & 123.20 & 128,6499 \\
CCC & 124,70 & 120,60 & 117,80 & 124,80 & 120,90 & 123,80 & 122,0999 \\
SADH & 100,20 & 97,20 & 92,30 & 117,40 & 92,70 & 111.10 & 101,9166 \\
CA & 86,80 & 94,90 & 96,60 & 93,90 & 91,00 & 95,10 & 93,0499 \\
CEPA & 125,70 & 121,10 & 140,70 & 121,40 & 133,20 & 112.50 & 125,7666 \\
& & & & & & &
\end{tabular}

O teste $\mathrm{F}$ para tratamentos apresentou valor de 18,6447 , significativo ao nível de $1 \%$ de probabilidade. A diferença mínima significativa pelo teste de Tukey, ao nível de $5 \%$ de probabilidade, foi da ordem de 15,5137. Verificando-se as diferenças entre as médias, observamos que as plantas controle e aquelas tratadas com CEPA e CCC mostraram peso médio do fruto em gramas, superior aos tratamentos com GA e SADH. O coeficiente de variação foi de $7,85 \%$.

\section{DISCUSSÃO}

Demonstrou-se pela análise estatística dos resultados da tabela 1 que não há diferença significativa entre as plantas tratadas com CCC e o controle, no que se refere ao peso total dos frutos. Tomateiros pulverizados com CCC mostraram-se com maior peso dos frutos, em relação aos tratados com SADH, GA e CEPA. Apesar do peso total dos frutos não ter sido afetado pela aplicação de CCC, CASTRO \& CHURATA-MASCA (1973 b) notaram aumento no peso total dos frutos de tomateiros, com aplicação de CCC, em condições de casa de vegetação. READ \& FIELDHOUSE (1970) também observaram aumento na produção de tomateiros tratados com CCC. CHURATA-MASCA \& CASTRO (1975) verificaram aumentos relativos na produção comercial de tomates com 
aplicações de CCC, porém observaram que as médias de produção em $\mathrm{t} / \mathrm{ha}$ não apresentaram diferenças significativas, o que se mostra de acordo com o resultado do presente ensaio. Não se observou variação no peso total dos frutos de tomateiros tratados com SADH, GA e CEPA, em relação ao controle. READ \& FIELDHOUSE (1970) notaram aumento na produção de tomateiros tratados com SADH. Apesar de não se observar, no presente trabalho, variação no peso total dos frutos de tomateiros tratados com GA, GRAY (1957), NEGRUCKIJ (1960) e RASPEVIN (1963) notaram aumento no peso dos frutos, em tomateiros pulverizados com GA. GUSTAFSON (1960) observou redução no peso total dos frutos de tomateiros cujas flores dos três primeiros cachos foram tratadas com GA. O resultado do presente experimento mostra-se semelhante ao obtido por MIRANDA NETO \& CHAVES (1969) que verificaram que tomateiros tratados com GA não apresentam diferenças na produção total de frutos em relação às plantas controle. Observou-se que aplicação de CEPA não modificou o peso total dos frutos de tomateiros, estando este resultado de acordo com aqueles obtidos por SIMS (1969) e CASTRO et alii (1972 b). Segundo IWAHORI et alii (1969), CEPA 250 ppm pode aumentar a produção de frutos; sendo que a concentração de $1.000 \mathrm{ppm}$ não afeta a produção total de frutos do tomateiro.

Verificou-se que a aplicação dos reguladores de crescimento não promoveu variação no número total de frutos produzidos nos tomateiros (tabela 2). CASTRO \& CHURATA-MASCA (1973 b) notaram aumento no número de frutos em tomateiros tratados com CCC $4.000 \mathrm{ppm}$, sob a forma de irrigação. READ \& FIELDHOUSE (1970) consideraram que tratamento com SADH pode promover aumento no número de frutos por planta de tomateiro. GUSTAFSON (1960), RASPEVIN (1963) e MIRANDA NETO \& CHAVES (1969) verificaram aumento no número de frutos em plantas de tomateiro tratadas com GA; sendo que SIMÃO et alii (1958) observaram redução no número total de frutos de tomateiros pulverizados com GA. CASTRO et alii (1972 b) notaram que a aplicação de CEPA não afetou o número de frutos por planta de tomateiro, o que se mostra de acordo com o resultado do presente trabalho.

Observou-se que plantas tratadas com CCC e CEPA não mostraram diferenças significativas no peso médio do fruto, em relação ao controle. Tratamentos com SADH e GA apresentaram redução no peso médio do fruto, em relação ao controle (tabela 3). Resultado semelhante ao do presente ensaio foi obtido por CASTRO \& CHURATA-MASCA (1973 b), os quais verificaram que o CCC não altera o peso médio do fruto do tomateiro, em relação ao controle. SAWNEY \& GREYSON (1971) notaram aumento no peso médio do fruto de tomateiro com aplicação de GA; sendo que RASPEVIN (1963) e MIRANDA NETO \& CHAVES (1969) observaram redução no peso médio do fruto devido ao tratamento com GA. Esse último resultado mostra-se semelhante ao obtido no presente ensaio. 


\section{CONCLUSÕES} clusões:

Os resultados obtidos neste ensaio, permitem as seguintes con-

1. Tratamento com cloreto de (2-cloroetil) trimetilamônio, ácido (2-cloroetil) fosfônico, ácido giberélico e ácido succínico -2,2- dimetilhidrazida não afeta o peso total dos frutos do tomateiro:

2. Aplicação de cloreto de (2-cloroetil) trimetilamônio, ácido (2-cloroetil) fosfônico, ácido giberélico e ácido succínico -2,2- dimetilhidrazida não promove variação no número total de frutos produzidos.

3. Tratamento com cloreto de (2-cloroetil) trimetilamônio e ácido (2-cloroetil) fosfônico não afeta o peso médio do fruto; sendo que aplicação de ácido succínico -2,2-dimetilhidrazida e ácido giberélico reduz o peso médio do fruto da cultivar "Miguel Pereira".

\section{SUMMARY}

EFFECTS OF GROWTH REGULATORS ON FRUITING OF TOMATO CULTIVAR "MIGUEL PEREIRA"

To study the influence on fruiting, (2-chloroethyl) trimethylammonium chloride (CCC) at concentration of $2,000 \mathrm{ppm}$, succinic acid-2,2-dimethylhydrazide $(\mathrm{SADH})(3,000 \mathrm{ppm})$, gibberellic acid (GA) (200 ppm), and (2-chloroethyl) phosphonic acid (CEPA) (200 ppm) were applied. Treatments with CCC, CEPA, GA and SADH did not affect the total weight of tomato fruits. The growth regulators did not promote changes in fruit number. Applications of CCC and CEPA did not affect the fruit weight average; however, spraying with SADH and GA reduced the fruit weight average.

\section{LITERATURA CITADA}

AWAD, M.; ARAMizU, A.K.; CHURATA-MASCA, M.G.C.; CASTRO, P.R.C. 1975 - Efeitos do ácido 2-cloroetilfosfônico (ethephon), das giberelinas, do confinamento en sacos pe polietileno e da temperatura no amadurecimento do tomate (Lycopersicon esculentum Mill.). Rev. de Agric. 50(1-2) : 69-76.

BABBITT, J.K; POWERS, M.J.; PATTERSON, M.E. 1973 - Effects of growth regulators on cellulase, polygalacturonase, respiration, color, and texture of ripening tomatoes. J. Amer. Soc. Hort. Sci. 98(1) : 77-81.

CÁSSERES, E. 1971 - Producción de hortalizas. Herrero Hermanos, Sucesores, México. 310 p. 
CASTRO, P.R.C.; CHURATA-MASCA, M.G.C. 1973a - Variações provocadas pelo ácido 2-hidroximetil 4-clorofenoxiacético na colheita de tomateiro do grupo Santa Cruz. Rev. de Agric. 48(2-3) : 59-68.

CASTRO, P.R.C.; CHURATA-MASCA, M.G.C. 1973b - Efeitos do cloreto de 2-cloroetil trimetilamônio na produtividade do tomateiro. Supl. Ciência e Cultura $25(6): 530$.

CASTRO, P.R.C.; CHURATA-MASCA, M.G.C.; MIRANDA FILHO, J.B. 1972a. Efeitos do ácido hidroximetil-2 cloro-4 fenoxiacético na frutificação de tomateiro do grupo Santa Cruz. Rev. de Agric. 47(1): 31-34.

CASTRO, P.R.C.; CHURATA-MASCA, M.G.C.; AWAD, M. 1972b. - Efeitos do ácido 2-cloroetilfosfônico na maturação de frutos do tomateiro (Lycopersicon esculentum Mill. cv. "São Sebastião"). An. Esc. Sup. Agr. "Luiz de Queiroz" 29: 159-168.

CHURATA-MASCA, M.G.C.; CASTRO, P.R.C. 1975 - Influências do cloreto de 2-cloroetil trimetilamônio (chlormequat) na produção de tomate rasteiro. Ciêtncia e Cultura $27(12)$ : 1339 .

GOMES, F.P. 1963 - Curso de estatística experimental. Universidarle de São Paulo. E.S.A. "Luiz de Queiroz", Piracicaba. 384 p.

GRAY, R.A. 1957 - Alteration of leaf size and shape and other changes caused by gibberellins in plants. Amer. J. Bot. 44(8): 674-682.

GUSTAFSON, F.G. 1960 - Influence of gibberellic acid on setting and development of fruits in tomato. Plant Physiol. 35(4): 521-523.

IWAHORI, S.; BEN-YEHOSHUA, S.; LYONS, J.M. 1969 - Effect of 2-chloroethanephosphonic acid on tomato fruit development and maturation. Bioscience 19:49-50.

MIRANDA NETO, A.T.; CHAVES, I.R.P. 1969 - Efeito da aplicação dos ácidos giberélico e paracloro-fenoxiacético em tomateiro. Rev. Ceres 16(89) : 178-192.

NEGRUCKIJ, S.F. 1960 - The effect of gibberellin on the growth, productivity and fruit shape in tomatoes. Fiziologiya Rastenii. $7:$ 734-735.

RASPEVIN, J.A. 1963 - Changes in tomatoes under the influence of gibberellin. Vestn. Sel'sk. Nauki 8(12): 131-134.

READ, P.E.; FIELDHOUSE, D.J. 970 - Use of growth retardants for increasing tomato yields and adaptation for mechanical harvest. J. Amer. Soc. Hort. Sci. 95(1) : 73-78.

SAWHNEY, V.K.; GREYSON, R.I. 1971 - Fruit size increase in tomato (Lycopersicon esculentum) through gibberellic acid treatment. Amer. J. Bot. 58: 460.

SIMÃO, S.; SERZEDELLO, A.; WHITAKER, W. 1958 - Ação do áci(lo giberélico sobre o tomateiro (Lycopersicon esculentum Mill.). Rev. de Agric. 33(3): 153-156.

SIMS, W.L. 1969 - Effects of ethrel on fruit ripening of tomatoes. California Agriculture $27(7): 12-14$.

WEAVER, R.J. 1972 - Plant growth substances in agriculture. W.H. Freeman and Company, San Francisco. 594 p. 